\title{
SEGURANÇA SOCIAL E DISTRIBUIÇÃO DO RENDIMENTO*
}

\author{
Carlos Almeida Andrade**
}

\begin{abstract}
No debate sobre a reforma da segurança social, tem sido apresentado o argumento de que um sistema público de repartição contemporânea tem uma maior preocupação redistributiva do que um sistema com uma componente de capitalização em contas pessoais, pelo que deve ser mantido, apesar de eventuais ineficiências. No entanto, apesar das intenções explícitas presentes na concepção dos actuais sistemas de segurança social, as regras de cálculo das pensões potenciam uma redistribuição perversa do rendimento, dos mais pobres para os mais ricos. A experiência de diversos países mostra que a progressividade da segurança social, quando existe, é pouco significativa e não sistemática. Em alguns países, os sistemas assumiram mesmo uma natureza regressiva. Depois de apresentadas várias justificações para estes resultados, recorre-se a uma simulação para avaliar a existência e o sentido do mesmo tipo de efeitos redistributivos em Portugal. Os resultados confirmam a natureza regressiva do actual sistema de repartição contemporânea. Finalmente, simulam-se os efeitos de algumas propostas recentes de alteração das regras de cálculo das pensões.
\end{abstract}

Palavras-chave: segurança social, pensões, repartição contemporânea, distribuição do rendimento, política social.

\footnotetext{
** Department of Economics and Related Studies, University of York.
} 


\section{INTRODUÇÃO}

A generalidade dos sistemas públicos de segurança social, tal como os conhecemos hoje, pretende desempenhar duas funções principais: (i) uma função de seguro, face às oscilações imprevistas no rendimento e face à incerteza quanto ao tempo de vida depois da reforma; e (ii) uma função de redistribuição. Esta coexistência de objectivos num mesmo sistema não é, no entanto, pacífica. Enquanto Atkinson (1987), por exemplo, classificava a segurança social como mais um mecanismo de combate à pobreza, Feldstein (1985) defendia que a poupança e a obrigatoriedade de adesão a um seguro deveriam constituir a sua verdadeira essência.

A crescente tomada de consciência dos problemas estruturais que afectam os sistemas públicos de segurança social em regime de repartição contemporânea tem contribuído para aumentar a contestação a esta mistura de objectivos no mesmo sistema ou, pelo menos, num mesmo pilar do sistema. É possível encontrar vários argumentos dentro desta linha de pensamento.

Em primeiro lugar, o de que um sistema de redistribuição de rendimento deve ter como destinatários todas as pessoas com um rendimento insuficiente e não apenas os idosos. Em certos países, argumenta-se, não faz sentido redistribuir a favor dos idosos como um grupo, uma vez que estes constituem mesmo a geração mais favorecida (por exemplo, no caso dos Estados Unidos). Faria sentido, assim, que a redistribuição de rendimento a favor dos idosos estivesse integrada num mecanismo geral de combate à pobreza.

Em segundo lugar, e no seguimento do argumento anterior, há quem entenda que a redistribuição de rendimento deve ser um objectivo e (como tal) um encargo de toda a sociedade e não apenas daqueles que, por receberem uma remuneração pelo seu trabalho, contribuem para o sistema de segurança social. Assim, deveria haver uma diversificação das fontes de redistribuição ou, em alternativa, esta deveria ser exclusivamente sustentada por receitas gerais do Estado.

Em terceiro lugar, e acima de tudo, argumenta-se também que a mistura de objectivos dentro do mesmo sistema tem prejudicado, quer a eficácia da redistribuição do rendimento, quer a própria solvabilidade da segurança social como mecanismo de repartição contemporânea. É precisamente este terceiro argumento que se pretende analisar aqui.

Nesse sentido, a secção seguinte começa por referir resumidamente os problemas estruturais da segurança social descrevendo, em seguida, a relação destes com o objectivo da redistribuição do rendimento. 
Argumenta-se aí que, contrariando as intenções explícitas dos sistemas públicos de repartição contemporânea, as regras de cálculo das pensões de velhice potenciam uma redistribuição perversa do rendimento, dos mais pobres para os mais ricos (para além de uma redistribuição não intencional entre gerações).

Recorrendo a um conjunto de estudos empíricos levados a cabo para diversos países, a Secção 3 analisa a experiência internacional ao nível dos efeitos redistributivos intrageracionais da segurança social, confirmando a existência generalizada de uma redistribuição perversa do rendimento. Na Secção 4, discutem-se as explicações possíveis para este resultado. A Secção 5 recorre a dados do mercado de trabalho português, bem como a algumas hipóteses demográficas, para simular os perfis de remunerações de diferentes categorias profissionais (e de rendimento). Aplicando a estes perfis as regras do sistema português de segurança social, averigua-se a existência e o sentido de eventuais efeitos redistributivos intrageracionais no nosso país. Finalmente, na Seç̧ão 6, são apresentadas as principais conclusões. Confirmando a tendência observada na maioria dos países, o actual sistema público de segurança social português, em regime de repartição contemporânea, parece tratar mais generosamente as categorias profissionais de maior rendimento, à custa das categorias profissionais mais pobres. Para além disto, e independentemente da categoria profissional, as mulheres parecem sair beneficiadas em relação aos homens.

\section{REPARTIÇÃO CONTEMPORÂNEA E DISTRIBUIÇÃO INTRAGE- RACIONAL DO RENDIMENTO: O PROBLEMA}

$\mathrm{Na}$ origem dos problemas da segurança social está o facto de as suas regras terem sido concebidas num contexto económico e demográfico bastante diferente do actual. Baseando-se num esquema de repartição contemporânea (ou pay-as-you-go), sem um stock de poupanças (relevante) para cobrir as obrigações futuras, a satisfação das responsabilidades do Estado para com as sucessivas gerações de trabalhadores está dependente (num sistema pay-as-you-go puro) do crescimento suficiente da massa salarial, sob a qual incidem as contribuições.

Os salários reais, no entanto, têm vindo a crescer cada vez menos ao longo dos últimos trinta anos. Por outro lado, em resultado da evolução 
das taxas de fertilidade e mortalidade, existem cada vez menos trabalhadores activos para sustentar as pensões dos reformados. Em suma, o crescimento da base contributiva do sistema de repartição já não é suficiente para acompanhar o crescimento das responsabilidades do Estado no pagamento de pensões, prevendo-se que, em Portugal, no caso de nada ser feito para reformar o sistema, as contribuições dos trabalhadores activos deixem de ser suficientes para financiar as pensões algures entre 2015 e 2020 (ver Comissão do Livro Branco da Segurança Social (CLBSS), 1998).

Nos últimos anos, têm vindo a ser introduzidos no sistema português de segurança social alguns ajustamentos, sem que se tenham alterado as suas regras essenciais. Exemplos destas medidas são o prolongamento da idade de reforma (no caso das mulheres), o aumento da taxa contributiva, a reformulação das regras de cálculo das pensões no sentido da diminuição do seu valor e, por último, a criação ou aumento de outros impostos com a afectação de receitas à segurança social (como é o caso do chamado "IVA social").

$\mathrm{Na}$ base deste tipo de actuação (isto é, ausência de uma reforma estrutural), tem sido apresentado o argumento de que um sistema público de repartição contemporânea tem, na sua natureza, uma maior preocupação redistributiva do que um sistema de capitalização em contas pessoais, ou mesmo do que um sistema misto, pelo que deve ser mantido apesar de eventuais ineficiências.

De facto, uma característica importante de um sistema de segurança social do tipo pay-as-you-go é a possibilidade de ser utilizado com fins redistributivos, tanto dentro de uma geração como entre diferentes gerações. Ao contrário do que acontece num sistema de capitalização, não existe uma ligação actuarial entre as contribuições pagas e os benefícios recebidos. As contribuições podem assim ser utilizadas, em parte, para financiar as prestações de outros beneficiários que se encontram em situação de carência. Esta possibilidade traduz-se na redistribuição intratemporal atrás mencionada, encontrando-se exemplos na garantia de uma pensão mínima, na existência de um regime não contributivo ou na diferenciação da actualização anual das pensões.

No entanto, os sistemas de repartição contemporânea, bem como os ajustamentos que têm sido feitos nas suas regras, podem ser responsáveis, ainda que não intencionalmente, por efeitos redistributivos perversos que contribuem para um aumento da desigualdade.

Por um lado, o tipo de ajustamentos atrás referidos implica um retorno cada vez menor das contribuições para as novas gerações de pensionistas. 
Fala-se, neste caso, de efeitos redistributivos intergeracionais. O aumento das contribuições, por exemplo, beneficia a população reformada ou os trabalhadores activos de idade mais avançada, em prejuízo dos trabalhadores activos mais jovens. O mesmo pode acontecer com a diminuição dos benefícios, sempre que os interesses adquiridos das gerações mais próximas da reforma sejam salvaguardados.

Por outro lado, e para lá dos mecanismos de redistribuição explícitos (como a pensão mínima), as regras de um sistema de repartição contemporânea beneficiam determinados comportamentos no mercado de trabalho e favorecem determinadas categorias socioeconómicas, implicando assim uma redistribuição implícita a favor de certos grupos, à custa de outros.

A questão dos efeitos redistributivos tem sido um dos aspectos mais negligenciados no debate sobre a reforma da segurança social portuguesa. A discussão tende a centrar-se no tipo de medidas adequadas para prolongar a sustentabilidade do sistema de pensões, quer dentro da actual lógica de financiamento, quer num sistema renovado, parecendo assumir-se como princípio não disputado a natureza equitativa do actual sistema de repartição contemporânea. Quando isto não acontece, a natureza "injusta" da segurança social portuguesa é apenas conotada com a existência, em diversos casos, de pensões de valor muito baixo, ignorando-se que, mais do que a ausência de uma redistribuição relevante a favor dos pobres, pode existir mesmo uma redistribuição do rendimento a favor dos trabalhadores mais ricos, à custa dos trabalhadores mais pobres.

\section{RESULTADOS DA LITERATURA}

Este tipo de efeitos redistributivos não declarados de um sistema de segurança social tem sido observado empiricamente em vários países. Um dos trabalhos mais citados neste domínio deve-se a Hurd e Shoven (1985). Baseando-se numa amostra de agregados familiares norte-americanos, estes autores compararam a rendibilidade das contribuições por quartis de riqueza, dentro de uma mesma coorte, concluindo que as taxas de rendibilidade não variam significativamente de quartil para quartil sendo mesmo, em algumas coortes, superiores para o terceiro e quarto quartis. São, assim, anulados os objectivos redistributivos do sistema. 
Análises mais recentes da realidade americana (e também mais sofisticadas, quer do ponto de vista dos dados utilizados, quer das metodologias seguidas) têm sistematicamente obtido conclusões semelhantes. Feldstein e Liebman (2000) e Kotlikoff, Smetters e Walliser (2000) simulam o impacte distributivo de uma transição do actual sistema pay-as-you-go americano para um sistema com uma componente de capitalização privada. Os resultados obtidos são muito semelhantes, indicando que, apesar de alguns custos no curto prazo (resultantes da transição entre sistemas), a introdução de capitalização privada na segurança social aumentaria o bem-estar dos mais pobres, mesmo na ausência de um mecanismo explícito de redistribuição no novo sistema. Bosworth, Burtless and Sahm (2000) comparam uma transição do mesmo tipo com a manutenção do sistema, acompanhada de um aumento de contribuições suficiente para manter a sua solvabilidade. Apesar de concluírem que o bem-estar dos trabalhadores mais pobres seria maior com a segunda alternativa (manter o sistema), não foram encontradas diferenças significativas, entre as duas opções de reforma, ao nível da distribuição de rendimento. Uma nota discordante em relação a estas conclusões é encontrada em Deaton, Gourinchas e Paxson (2000), que também comparam os mesmos sistemas alternativos. Segundo estes autores, a desigualdade no rendimento é uma consequência da história acumulada dos diferentes riscos individuais, quer ao nível das remunerações quer ao nível da rendibilidade dos activos. Ao fazer um pooling dos riscos individuais, a segurança social limita o crescimento da desigualdade ao longo do ciclo de vida. Finalmente, Cubeddu (2000) sugere que os benefícios de uma privatização da segurança social americana seriam menores para os brancos, para as mulheres e para os não licenciados.

O mesmo sentido geral das conclusões pode ser encontrado num conjunto de estudos relativos à segurança social na Europa. Analisando o sistema de pensões sueco (anterior à reforma de 2000), Stahlberg (1994) confirma a inexistência de uma redistribuição sistemática a favor das categorias socioeconómicas mais baixas. Para além disso, identifica uma redistribuição a favor dos homens e em prejuízo das mulheres. Gil e Lopez-Casasnovas (1997) observam um impacte significativamente diferenciado do sistema público de segurança social espanhol ao nível do rendimento, do sexo e do estado civil. Os trabalhadores com rendimentos mais elevados são (em três coortes diferentes) os que obtêm as maiores transferências líquidas do sistema, quer em termos absolutos, quer em termos relativos, observando-se também, ao nível deste grupo, a taxa 
interna de rendibilidade mais elevada. Gil e Lopez-Casasnovas concluem, então, que o sistema espanhol de segurança social gera um "impacte social regressivo" (Gil e Lopez-Casasnovas, 1997: p.22). Ao nível da redistribuição por sexo e estado civil, observa-se um ganho das mulheres em relação aos homens (apesar de as primeiras apresentarem, em média, salários inferiores) e um ganho dos pensionistas casados em prejuízo dos solteiros.

Castellino (1995) avalia os efeitos redistributivos do sistema de pensões italiano (anterior à reforma iniciada em 1995, que introduziu um regime de capitalização pública), enfatizando a correlação entre a rendibilidade das contribuições e a dinâmica de evolução de remunerações ao longo da vida de um trabalhador. Simulando seis carreiras profissionais típicas, diferenciadas pela taxa de crescimento das remunerações, e aplicando as regras do (antigo) sistema, Castellino observa uma taxa de rendibilidade de $5,74 \%$ para os indivíduos da categoria socioeconómica mais elevada e apenas de 3,21\% para os trabalhadores com uma progressão de remunerações mais lenta. Comparando o antigo sistema pay-as-you-go italiano com o sistema reformado, Borella (2001) mostra que o sistema de capitalização permite aos indivíduos dos decis de remuneração mais baixos obter taxas de substituição (dos salários pelas pensões) mais elevadas do que no sistema antigo, à custa dos indivíduos dos decis superiores, cuja taxa de substituição obtida após a reforma é inferior.

Os resultados apresentados ilustram a ideia de que os sistemas de segurança social do tipo pay-as-you-go tendem a ser responsáveis por uma redistribuição perversa e não declarada do rendimento, dentro de uma mesma geração. A secção seguinte procura analisar as explicações possíveis para estes resultados.

\section{EFEITOS REDISTRIBUTIVOS PERVERSOS: JUSTIFICAÇÕES}

A explicação mais imediata para esta redistribuição perversa do rendimento encontra-se no facto de as pessoas de rendimentos elevados beneficiarem de uma esperança de vida maior conseguindo, assim, receber pensões durante mais anos do que as pessoas pobres. Estas têm, em geral, acesso a uma vida menos saudável, habitando em casas com piores condições e fazendo uma dieta alimentar mais pobre do ponto de vista nutricional. Por outro lado, as pessoas com maiores rendimentos têm 
um acesso mais facilitado a medicamentos e a cuidados de saúde de qualidade (incluindo cuidados preventivos). ${ }^{2}$

É sempre possível argumentar que uma das funções da segurança social consiste precisamente em servir de seguro contra a eventualidade de se viver até muito tarde, sendo isso que estaria a acontecer com as pessoas mais ricas. Acontece, porém, que esta diferença na longevidade não é aleatória, mas sim previsível (há diferenças conhecidas no risco de mortalidade, em cada idade, associado à categoria social, económica ou profissional), implicando isso que deixemos de estar na presença de um seguro para passarmos a estar perante uma redistribuição de rendimento a favor dos mais abastados.

Uma segunda justificação para os efeitos redistributivos perversos de um sistema de pensões do tipo pay-as-you-go encontra-se no facto de, muitas vezes, as pessoas ligadas a categorias socioeconómicas inferiores entrarem mais cedo na força de trabalho, sem que o período contributivo adicional associado represente algo de significativo em termos de direito a uma pensão. Em Portugal, no sistema de pensões dos funcionários públicos, o número de anos de contribuições para lá dos 36 já não conta para o cálculo da pensão. No sistema geral, o mesmo era verdade, até 1999, para lá de 40 anos (e em Espanha, actualmente, para lá de 35 anos). Esta fonte de desigualdade pode ser agravada, como acontece em certos países da América Latina (ver James, 1997), mas também em alguns países da Europa, como a Alemanha ou a Hungria (ver World Bank, 1994), pelo facto de os estudantes universitários, geralmente com maiores rendimentos, beneficiarem de um período contributivo virtual para efeitos de determinação de uma pensão. Isto é, não fazendo, de facto, contribuições para o sistema, o período dos seus estudos superiores é contabilizado como se essas contribuições existissem.

Uma terceira justificação encontra-se no facto de, em geral, as regras privilegiarem, para efeitos de cálculo das pensões, os últimos anos de remunerações antes da idade de reforma (variando entre países, geralmente num período de 1 a 15 anos antes do momento da reforma). Uma vez que as pessoas de maiores rendimentos apresentam, tipicamente, perfis de remuneração com um crescimento mais pronunciado, elas tenderão a obter uma maior rendibilidade das contribuições.

Em quarto lugar, ao serem aplicadas as mesmas regras contributivas a pobres e ricos, o nível de consumo sacrificado devido à participação no sistema de segurança social será superior para os primeiros. De facto, o montante das contribuições pode ser compensado pelos mais abastados através da diminuição da poupança noutros instrumentos, permitindo 
assim manter o nível de consumo. Esta possibilidade dificilmente estará ao alcance dos mais pobres. Por outro lado, ao fazer incidir as contribuições exclusivamente sobre os salários e através de uma taxa uniforme (como acontece na generalidade dos países), a tributação implícita num sistema de segurança social do tipo pay-as-you-go abrange a totalidade do rendimento dos mais pobres, uma vez que estes, em regra, vivem exclusivamente do trabalho, mas apenas uma parte do rendimento dos mais ricos, que beneficiam de outras fontes de rendimento. Por último, a generalidade dos sistemas públicos de segurança social (como o português) permite a dedução, nos impostos, das contribuições, o que favorece igualmente os trabalhadores de rendimentos mais elevados em relação aos trabalhadores pobres. Esta última vantagem é também potenciada pelo maior nível de informação dos trabalhadores ricos e pela maior capacidade de estes compreenderem e aproveitarem as oportunidades oferecidas pela lei fiscal.

Em certos casos, no entanto, o problema não advém do estabelecimento de regras iguais para ricos e pobres, mas sim de privilégios atribuídos aos primeiros. De acordo com o World Bank (1994), os trabalhadores mais qualificados e os funcionários públicos beneficiam, em diversos países, de condições de reforma especialmente vantajosas. Em Portugal, os funcionários públicos (em média, com uma remuneração bastante superior à da generalidade dos trabalhadores) podem reformar-se mais cedo e com uma pensão igual a $100 \%$ do salário auferido no ano anterior ao da reforma (em comparação com os $80 \%$ de uma remuneração média calculada com base nos melhores 10 de entre os últimos 15 anos, para os outros trabalhadores). Na Hungria, os trabalhadores mais qualificados do sector dos serviços tinham a possibilidade de se reformarem 15 a 25 anos mais cedo que os operários sem perda substancial de direitos. ${ }^{3}$ Em Itália, antes da reforma iniciada em 1995, os funcionários públicos podiam reformar-se após 20 anos de trabalho e de contribuições. No sector privado, algumas categorias profissionais mais qualificadas podiam igualmente reclamar a totalidade dos direitos a uma pensão de reforma apenas com 35 anos de carreira contributiva (menos 5 do que a generalidade dos trabalhadores). Finalmente, em certos países (por exemplo, no Equador ou nas Filipinas), as reservas dos fundos de pensões públicos são utilizadas para conceder empréstimos a trabalhadores de rendimentos elevados, a taxas de juro reais negativas.

Uma última justificação para este tipo de efeitos redistributivos, que se relaciona, sobretudo, com os sistemas de segurança social de países 
menos desenvolvidos, consiste na utilização de receitas gerais do Estado para o financiamento das pensões de reforma. Embora o recurso a receitas gerais aconteça também noutros países, e sob diversas formas, o seu efeito perverso é particularmente acentuado nos países menos desenvolvidos. Por um lado, porque assume aí uma natureza mais sistemática; por outro lado, porque a cobertura dos sistemas de segurança social é relativamente pequena e concentrada nas pessoas de maiores rendimentos. Na Guatemala, por exemplo, cerca de um terço das receitas gerais do Estado - obtidas a partir de toda a população - são utilizadas para financiar as pensões de reforma, embora o sistema de segurança social cubra apenas um terço da população.

Uma última palavra em relação à redistribuição implícita entre sexos. Aqui é possível identificar efeitos contraditórios. Por um lado, a tendência geral parece ser a da redistribuição a favor das mulheres, explicada não só por uma maior esperança de vida mas também (e em função disso) pelo facto de beneficiarem - mais do que os homens - de pensões de sobrevivência e viuvez. Por outro lado, os sistemas pay-as-you-go não favorecem percursos profissionais em part-time, ou com interrupções, normalmente associados a padrões de trabalho femininos. Adicionalmente, existe ainda alguma discriminação das mulheres, quer em termos salariais, quer ao nível de promoções e progressão na carreira. Quando estes efeitos se sobrepõem ao efeito da longevidade, observa-se, como na Suécia, uma redistribuição a favor dos homens. ${ }^{4}$

\section{A REDISTRIBUIÇÃO INTRAGERACIONAL NA SEGURANÇA SOCIAL PORTUGUESA}

No seu relatório final, a Comissão do Livro Branco da Segurança Social (CLBSS) fazia referência às desigualdades e ineficiências crescentes do sistema de pensões português: "O mecanismo de repartição pura está a tornar-se progressivamente inequitativo, regressivo, ineficiente e gerador de potenciais conflitos intergeracionais" (CLBSS, 1998: p. 105). Entre as razões apresentadas, contava-se a evidência de que os ricos vivem mais tempo que os pobres, consumindo assim pensões de reforma durante mais anos; o facto de as carreiras dos contribuintes de menores níveis salariais (incluindo as mulheres) terem acréscimos médios anuais inferiores aos dos contribuintes de níveis salariais superiores; a 
ideia de que alguns contribuintes - sobretudo aqueles com maior nível de instrução e com mais contactos sociais - conseguem aproveitar melhor determinados "espaços abertos" da lei, manipulando estrategicamente o valor declarado das contribuições, de modo a fazer a sua concentração nos últimos anos da vida activa; e, por último, o facto de as isenções fiscais aos pensionistas beneficiarem mais os titulares de pensões mais elevadas. Esta combinação perversa entre o sistema fiscal e a segurança social levou a que as taxas de substituição (do salário pela pensão) sejam, em geral, mais elevadas nos rendimentos mais altos. Enquanto que um salário líquido de 50 contos (250 Euros) está associado a uma taxa de substituição de 89,9\%, um salário líquido de 600 contos (3 mil Euros) está associado a uma taxa de substituição de 91,8\% (CLBSS, 1998: p.108).

Esta secção tem como objectivo averiguar, através de um pequeno exercício, a existência e o sentido de eventuais efeitos redistributivos intrageracionais no sistema português de segurança social.

Apenas uma nota prévia: a análise levada a cabo incide exclusivamente sobre o regime geral da Segurança Social, deixando-se, assim, de fora, quer o sistema dos funcionários públicos (da Caixa Geral de Aposentações), quer os diversos subsistemas profissionais (como os dos trabalhadores do sector bancário) quer, ainda, e sobretudo, o regime não contributivo da Segurança Social. Neste último, é evidente que a redistribuição existe e favorece os mais pobres, através das pensões sociais ou do complemento social (que permite o pagamento de uma pensão mínima). Interessa-nos, pois, avaliar a redistribuição de rendimento apenas ao nível do regime geral e no que respeita os contribuintes que conseguem adquirir o direito a uma pensão de valor superior à pensão mínima.

\subsection{Perfis de remunerações}

Uma vez que não dispomos de perfis observados na realidade, o primeiro passo deste exercício consiste na construção de perfis de remunerações - artificiais mas plausíveis - para diferentes categorias profissionais e de rendimento (uma forma de aproximação à realidade seguida também por Castellino (1995) e por Rake, Falkingham e Evans (1999), por exemplo). Desta forma, os resultados a obter pretendem apenas pôr em evidência a natureza intrínseca das regras da segurança 
social portuguesa, ao nível da redistribuição de rendimento. Isto é, dado um determinado perfil de remuneração associado ao contribuinte-tipo X, pretende-se ilustrar a forma como as regras do sistema tratam X, relativamente ao tratamento que é atribuído a outros contribuintes-tipo $\mathrm{Y}$ e Z. Contudo, para tornar a análise interessante, a referida natureza intrínseca do sistema de pensões deve depender de algumas características económicas e sociais do mercado de trabalho português. Neste sentido, os perfis construídos pretendem reflectir, o mais fielmente possível, o verdadeiro ritmo de evolução real das remunerações, bem como a esperança de vida das diferentes categorias de rendimento.

As categorias de rendimento consideradas baseiam-se numa classificação dos Quadros do Pessoal do Ministério do Trabalho e Solidariedade (MTS): Profissionais Não Qualificados, Profissionais Qualificados e Quadros Superiores - uma categoria baixa, uma outra média e uma terceira alta em termos de rendimento auferido. Dentro de cada categoria, considerou-se ainda uma divisão entre os sexos masculino e feminino. Obtiveram-se, assim, seis perfis de remunerações.

A construção dos perfis segue, em linhas gerais, uma sugestão apresentada por Creedy (1992) e que se aplica às situações em que o investigador não tem acesso a uma base de dados com histórias reais, e completas, de remunerações e períodos contributivos, mas apenas a informação cross-section sobre as remunerações de uma pequena amostra (como é o nosso caso).

No cenário definido por aquele autor, partindo de um cross-section de remunerações de indivíduos com diferentes idades, são assumidas duas hipóteses: (i) as diferenças entre as sucessivas coortes devem-se apenas à idade $(t)$ e ao tempo medido em anos (d); (ii) o efeito "idade" é quadrático e o efeito "tempo" é linear, implicando uma taxa de crescimento real das remunerações $(\beta)$ constante.

Considere-se $y_{t, d}$ como a remuneração média, em logaritmo, de uma pessoa de idade $t$ no ano $d$. Estimando os parâmetros de um modelo simples do tipo

$$
\begin{gathered}
y_{t, d}=\alpha_{0}+\alpha_{1} t+\alpha_{2} t^{2}+\beta d \Leftrightarrow \\
\Leftrightarrow y_{t, d}=\left(\alpha_{0}+\beta d\right)+\alpha_{1} t+\alpha_{2} t^{2} \Leftrightarrow \\
\Leftrightarrow y_{t, d}=\alpha_{0}^{\prime}+\alpha_{1} t+\alpha_{2} t^{2}
\end{gathered}
$$


a partir da informação cross-section disponível, Creedy (1992) propõe que o perfil de remunerações completo de qualquer grupo etário ou de qualquer categoria socioeconómica possa ser obtido através de

$$
\hat{y}_{t, d}=\hat{\alpha}_{0}^{\prime}+\left(\hat{\alpha}_{1}+\beta^{*}\right) t+\hat{\alpha}_{2} t^{2}
$$

em que $\hat{y}_{t, d}$ é a remuneração média estimada, em logaritmo, do grupo em questão, $\hat{\alpha}_{0}^{\prime}, \hat{\alpha}_{1}$ e $\hat{\alpha}_{2}$ são os parâmetros estimados no modelo (4.1) em cima e $\beta^{*}$ é a taxa de crescimento real das remunerações (ou a taxa de crescimento da produtividade) específica do grupo que se pretende analisar, e cujo valor, obtido através de informação externa ao modelo, é assumido constante ao longo do período em análise. Perfis de remuneração lifetime são então construídos com base em perfis cross-section. ${ }^{5}$

Os perfis que a seguir se apresentam foram construídos a partir de informação cross-section apresentada em CLBSS (1998), relacionando o nível de remuneração médio dos trabalhadores portugueses com determinados níveis etários. As estimativas obtidas a partir dessa informação foram depois complementadas com informação não publicada dos Quadros do Pessoal de 1998 (obtida directamente pelo autor no Ministério do Trabalho e Solidariedade), relativa ao crescimento médio anual da produtividade segundo a categoria profissional e sexo, o que permitiu calibrar o modelo sugerido por Creedy (1992) e assim construir os perfis específicos de cada um dos grupos em causa.

Na Figura 1, observam-se os seis perfis de remunerações estimados por este processo, sendo possível constatar o mesmo tipo de diferenças entre categorias de rendimento e sexo referidas nas secções anteriores. 
Figura 1

PERFIS DE REMUNERAÇÕES

Homens

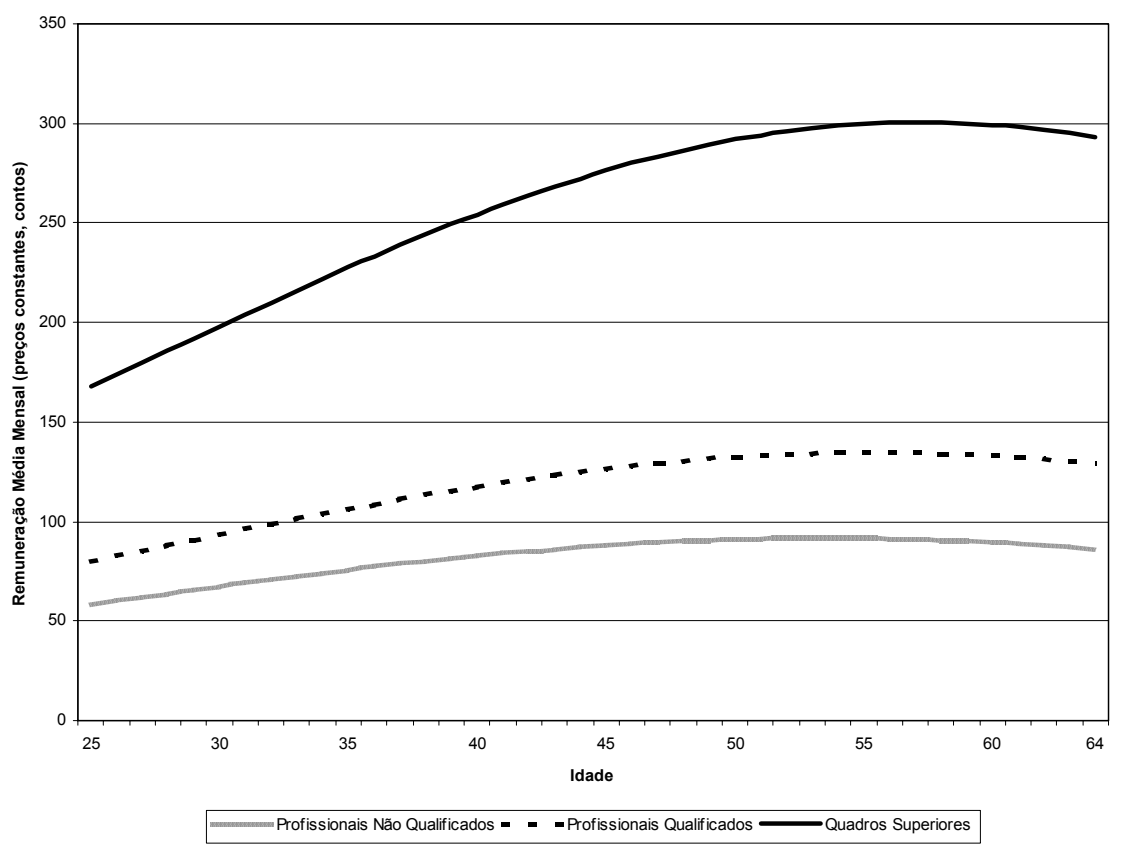

Mulheres

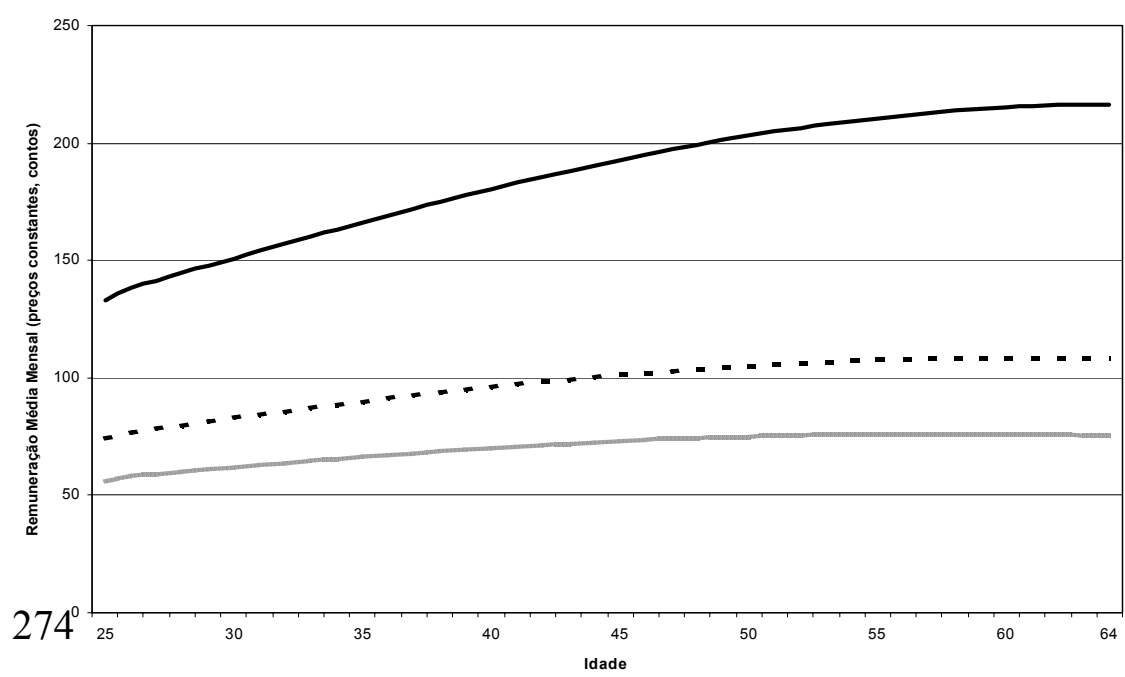

Profissionais Não Qualificados - - Profissionais Qualificados — Quadros Superiores 


\subsection{Esperança de Vida}

Os perfis de remunerações servem de base para a simulação das carreiras contributivas. Para estimar a duração dos períodos de reforma, durante os quais as pensões são recebidas, é necessário considerar uma diferenciação da esperança de vida, de acordo com as categorias de rendimento.

Santos Lucas (1985), citado em CLBSS (1998), refere que a probabilidade de morrer em Portugal está associada à classe social. Segundo aquele autor, em 1981, um trabalhador agrícola tinha, em média, uma probabilidade de morrer mais do que três vezes superior à dos administradores públicos e privados. Mais recentemente, Giraldes (1996), também citado por CLBSS (1998), analisou o comportamento das taxas de mortalidade padronizadas segundo seis grupos ocupacionais. As conclusões confirmaram, nos homens, a associação entre mortalidade e risco ocupacional, sendo no entanto pouco claras no que respeita às mulheres. Em relação a Espanha, Regidor et al. (1996) mostrou que, para um valor normalizado de 1 relativo à taxa de mortalidade dos gestores $\mathrm{e}$ administradores, as taxas de mortalidade dos trabalhadores manuais e dos trabalhadores agrícolas eram, respectivamente, de 1,72 e 1,56.

Por uma questão de conveniência, face aos grupos de rendimento adoptados neste exercício, optou-se por recorrer a um resultado apresentado por Brown (1997), segundo o qual existe evidência (relativamente a dados canadianos) de um diferencial de $15 \%$ na esperança de vida aos 60 anos, entre as categorias superior e inferior de rendimento.

De acordo com o Instituto Nacional de Estatística (1999), a esperança de vida para os homens de 65 anos é, em Portugal, de 14,31 anos, enquanto que para as mulheres é de 17,8 anos. Assume-se, como hipótese, que estes valores correspondem ao nosso grupo socioeconómico médio, o dos Profissionais Qualificados. Os valores da esperança de vida para os outros grupos, considerando o diferencial de $15 \%$ acima referido, são apresentados no Quadro 1. ${ }^{6}$ 
Quadro 1

ESPERANÇA DE VIDA AOS 65 ANOS

\begin{tabular}{|l|c|c|}
\hline & Homens & Mulheres \\
\hline Quadros Superiores & 15,3 & 19,04 \\
Profissionais Qualificados & 14,3 & 17,8 \\
Prof. Não Qualificados & 13,3 & 16,55 \\
\hline
\end{tabular}

Fonte: INE e cálculos do autor

\subsection{Cálculo das Pensões de Reforma}

O passo seguinte na simulação consiste em aplicar as regras da Segurança Social portuguesa, tal como descritas em MTS (2001). Resumidamente, a pensão por velhice no regime geral é atribuída a partir dos 65 anos a todos os beneficiários com um mínimo de 15 anos (seguidos ou interpolados) com registo de remunerações. ${ }^{7}$ A taxa contributiva, incidindo sobre as remunerações, é de $34,75 \%$. O montante da pensão de velhice é igual a $2 \%$ da remuneração média, por cada ano civil com registo de remunerações. Por sua vez, a remuneração média é dada pelo total das remunerações dos 10 anos civis com remunerações mais elevadas, de entre os últimos 15 anos antes da reforma, divididos por 140 (10 anos multiplicados por 14 meses de remunerações)

Para se proceder à simulação do valor das pensões, torna-se necessário considerar ainda algumas hipóteses adicionais. No cenário-base, assume-se que todos os indivíduos em análise apresentam a totalidade da carreira profissional com registo de remunerações. Assume-se ainda que a idade de entrada no mercado de trabalho acontece aos 25 anos e é igual para todos. Significa isto que a carreira contributiva considerada é de 40 anos. Sabe-se que, na realidade, o período contributivo médio dos actuais pensionistas é bastante inferior a 40 anos (não ultrapassando os 30 anos no caso dos homens e os 20 anos no caso das mulheres). Isto deve-se sobretudo a dois factores: por um lado, o sistema português de segurança social não atingiu ainda a maturidade, pelo que a carreira contributiva típica não pode ainda atingir os 40 anos; por outro lado, foi muito facilitada, durante o passado, a manipulação estratégica das carreiras contributivas, permitindo que, em muitos casos, se concentrassem as contribuições nos últimos anos antes da 
reforma, apenas num número de anos suficiente para se assegurar o chamado "prazo de garantia" de uma pensão (actualmente de 15 anos). É previsível que qualquer destas duas restrições se irá esbater com o passar dos anos, pelo que a carreira contributiva típica tenderá no futuro para os 40 anos aqui assumidos.

No cenário-base, assumem-se, por fim, mais quatro hipóteses: (i) não existe mobilidade entre classes; (ii) não existe manipulação estratégica das remunerações, de forma a concentrá-las no fim da carreira; (iii) nenhum indivíduo faz a antecipação ou o adiamento da idade de reforma, isto é, todas as pessoas se reformam aos 65 anos; (iv) finalmente, assume-se que o valor real da pensão é mantido ao longo da totalidade do período de reforma (que coincide com a esperança de vida aos 65 anos).

\subsection{Resultados}

A análise dos resultados levada a cabo a seguir tem como critério exclusivo uma avaliação da redistribuição intratemporal implícita no sistema. Deste modo, apresentam-se, relativamente aos vários cenários considerados, os seguintes indicadores:

(i) o rácio dos valores actualizados dos benefícios e custos associados à participação no sistema, obtido a partir das seguintes expressões:

$$
\begin{aligned}
& V A B e n=\sum_{t=65}^{M} P_{t}(1+i)^{-(t-24)} \\
& V A \text { Cont }=\sum_{t=25}^{64} \bar{W}_{t} c_{t}(1+i)^{-(t-24)} \\
& R_{B / C}=\frac{V A B e n}{V A C o n t}
\end{aligned}
$$

onde VABen, VACont e $R_{B / C}$ são, respectivamente, o valor actualizado dos benefícios, o valor actualizado das contribuições e o rácio entre o primeiro e o segundo; $P t$ é o valor anual em pensões recebido por um reformado de idade $t, M$ é a idade da morte do pensionista, $i$ é a taxa de desconto, $\bar{W}_{t}$ é o valor anual das remunerações recebidas por um trabalhador de idade $t$, a preços constantes e $c_{t}$ é a taxa contributiva. 
(ii) a taxa interna de rendibilidade $(r)$ dessa participação, determinada pela seguinte equação:

$$
\sum_{t=65}^{M} P_{t}(1+r)^{-(t-24)}=\sum_{t=25}^{64} \bar{W}_{t} c_{t}(1+r)^{-(t-24)}
$$

Para além do cenário-base, são apresentados resultados relativos a um conjunto de cenários alternativos, construídos a partir da alteração de algumas hipóteses inicialmente assumidas. Em todos os cenários foi utilizada uma taxa de desconto de $3 \%$. Nos estudos analisados nas secções anteriores, foi observada a utilização de taxas entre os $2 \%$ e os $6 \%$. Parece-nos, no entanto, que uma taxa de $3 \%$ é um valor razoável, correspondendo aproximadamente à rendibilidade de um activo com pouco risco. Gil e Lopez-Casasnovas (1997) utilizam o mesmo valor na sua simulação dos efeitos redistributivos do sistema de Segurança Social espanhol, com o argumento de que se trata de um valor próximo da taxa de crescimento de longo prazo da economia.

\section{(i) Cenário-base}

Os resultados para o cenário-base são apresentados no Quadro 2, a seguir.

Quadro 2

RESULTADOS DO CENÁRIO-BASE

\begin{tabular}{|l|c|c|}
\hline & TIR & Rácio B/C \\
\hline Homens & $(\%)$ & \\
Quadros Superiores & $-0,002$ & 0,446 \\
Profissionais Qualificados & $-0,356$ & 0,411 \\
Prof. Não Qualificados & $-0,740$ & 0,376 \\
\hline Variância & 0,1362 & - \\
\hline & & \\
Mulheres & $(\%)$ & \\
Quadros Superiores & 0,820 & 0,529 \\
Profissionais Qualificados & 0,504 & 0,484 \\
Prof. Não Qualificados & 0,200 & 0,447 \\
\hline Variância & 0,0961 & - \\
\hline
\end{tabular}


Os resultados apontam para a natureza regressiva do regime geral da segurança social portuguesa. A rendibilidade obtida pelas categorias de maiores rendimentos é sistematicamente superior à obtida pelas categorias com rendimentos mais baixos. Por outro lado, constata-se também uma redistribuição a favor das mulheres, que obtêm taxas internas de rendibilidade (TIR) superiores às dos homens (obtendo estes rendibilidades negativas). É importante notar que os perfis de remunerações foram obtidos a partir de hipóteses bastante conservadoras, no que respeita ao crescimento real dos salários. Os valores negativos das rendibilidades (quando observados) devem, por isso, ser interpretados com cuidado. Um cenário de crescimento mais rápido dos salários implicaria taxas de rendibilidade superiores e, eventualmente, positivas. No entanto, a análise aqui levada a cabo preocupa-se apenas com a comparação das rendibilidades entre sexos e categorias profissionais, não sendo especialmente relevante o valor absoluto da TIR. Uma hipótese mais generosa em termos de crescimento dos salários não alteraria, por isso, o sentido dos efeitos redistributivos.

(ii) Cenário 2: Consideração de toda a carreira no cálculo da "remuneração média"

Recentemente, o Governo português propôs a alteração da fórmula de cálculo da pensão estatutária no sentido de se passar a considerar, no cálculo da remuneração média, as remunerações de toda a carreira profissional e não apenas as 10 melhores dos últimos 15 anos antes da reforma. Prevê-se que esta medida entre em vigor no ano de 2016. O cenário 2 introduz esta alteração, mantendo constantes todas as outras hipóteses consideradas no cenário-base. Os resultados são apresentados no Quadro 3, a seguir. 
Quadro 3

RESULTADOS DO CENÁRIO 2

\begin{tabular}{|l|c|c|}
\hline & TIR (\%) & Rácio B/C \\
\hline Homens & $-0,577$ & 0,385 \\
Quadros Superiores & $-0,860$ & 0,362 \\
Profissionais Qualificados & $-1,172$ & 0,338 \\
Prof. Não Qualificados & 65,0 & - \\
\hline Índice da Variância* & & \\
\hline & & \\
Mulheres & 0,319 & 0,459 \\
\hline Quadros Superiores & 0,127 & 0,436 \\
Profissionais Qualificados & $-0,079$ & 0,414 \\
\hline Prof. Não Qualificados & 41,2 & - \\
\hline Índice da Variância* & & \\
\hline
\end{tabular}

* Cenário-Base $=100$

Observa-se uma deterioração da taxa interna de rendibilidade para todos os grupos socioeconómicos, agravando-se também substancialmente o rácio benefícios/custos. Isto não surpreende, uma vez que a remuneração média que serve de base ao cálculo das pensões é diminuída pela contabilização de toda a carreira profissional. $\mathrm{O}$ resultado principal, no entanto, é o facto de a regressividade do sistema ser atenuada através desta alteração das regras. Apesar dos resultados inferiores, a dispersão das rendibilidades é substancialmente reduzida e, de uma forma mais clara, no caso das mulheres. Este resultado é confirmado através da comparação entre a pensão inicial do cenário 2 e a pensão inicial do cenário-base. Enquanto que os homens e as mulheres, na categoria dos Profissionais Não Qualificados, conseguem manter $90 \%$ e $92,6 \%$ da pensão inicial, respectivamente, os Quadros Superiores vêem a sua pensão inicial reduzida para $86,4 \%$ e $86,8 \%$, respectivamente.

(iii) Cenário 3: Aumento da Idade de Reforma

Uma das medidas que tem sido seguida em vários países como forma de prolongar a solvabilidade dos sistemas de Segurança Social é o prolongamento da idade de reforma. Embora não esteja prevista 
formalmente em Portugal, esta medida é constantemente tida como inevitável, até como resposta ao aumento da esperança de vida observado ao longo dos últimos anos. O Cenário 3 simula os dois cenários anteriores, alterando apenas a idade da reforma dos 65 para os 70 anos.

a) Apresentam-se, em primeiro lugar, os resultados de um cenário equivalente ao cenário-base, excepto na idade de reforma, que aumenta para os 70 anos.

Quadro 4

RESULTADOS DO CENÁRIO 3A

\begin{tabular}{|l|c|c|}
\hline & TIR (\%) & Rácio B/C \\
\hline$\underline{\text { Homens }}$ & $-1,701$ & 0,309 \\
Quadros Superiores & $-2,268$ & 0,272 \\
Profissionais Qualificados & $-2,933$ & 0,236 \\
Prof. Não Qualificados & 279,1 & - \\
\hline Índice da Variância* & & \\
\hline & & \\
Mulheres & $-0,304$ & 0,408 \\
\hline Quadros Superiores & $-0,716$ & 0,364 \\
Profissionais Qualificados & $-1,117$ & 0,328 \\
\hline Prof. Não Qualificados & 171,9 & - \\
\hline Índice da Variância*
\end{tabular}

* Cenário-Base $=100$

Mantendo-se a regra dos 10 melhores anos de entre os últimos 15, o aumento da idade de reforma deteriora substancialmente a rendibilidade das contribuições para todas as categorias socioeconómicas, bem como o rácio entre benefícios e custos. Agrava-se também a desigualdade de tratamentos inerente ao sistema, em particular no caso dos homens, como comprova o aumento significativo da dispersão das rendibilidades. Comparando a pensão inicial com a pensão inicial do cenário-base, é possível observar aumentos entre $10,3 \%$ e $13,4 \%$, mas apenas se considerarmos uma alteração adicional nas regras de partida, isto é, admitindo que a carreira contributiva aumentou de 40 para 45 anos e que 
a pensão tem agora um limite máximo de $90 \%$ da remuneração média ( $2 \%$ por cada ano com registo de remunerações). Sendo este o caso, a regra favoreceria também mais as categorias de maior rendimento, que apresentam ganhos superiores em relação à pensão do cenário-base.

b) Alternativamente, podem-se avaliar os efeitos do aumento da idade de reforma no contexto de um sistema que considera toda a carreira profissional no cálculo da remuneração média (por oposição aos 10 melhores anos dos últimos 15). Os resultados são apresentados no Quadro 5 , em baixo.

Quadro 5

RESULTADOS DO CENÁRIO 3B

\begin{tabular}{|l|c|c|}
\hline & TIR (\%) & Rácio B/C \\
\hline Homens & $-2,269$ & 0,270 \\
\hline Quadros Superiores & $-2,761$ & 0,244 \\
Profissionais Qualificados & $-3,329$ & 0,217 \\
Prof. Não Qualificados & 206,5 & - \\
\hline Índice da Variância* & & \\
\hline & & \\
Mulheres & $-0,791$ & 0,357 \\
Quadros Superiores & $-1,072$ & 0,331 \\
Profissionais Qualificados & $-1,386$ & 0,305 \\
Prof. Não Qualificados & 92,2 & - \\
\hline Índice da Variância* &
\end{tabular}

* Cenário-Base $=100$

A rendibilidade diminui em relação ao cenário anterior, sendo mesmo o pior resultado até agora no que respeita aos homens. O efeito de regressividade é esbatido em comparação com o cenário 3a, o que era esperado dada a forma como a remuneração média é calculada. Comparando com os resultados do cenário-base, há uma deterioração forte da rendibilidade para todas as categorias e sexos e, no caso dos homens, um agravamento da regressividade. Apesar disso, a pensão inicial dos homens e mulheres Profissionais Não Qualificados/as é superior à do cenário-base em $1,3 \%$ e $4,8 \%$, respectivamente, ao passo 
que os Quadros Superiores retêm apenas, neste cenário, 98,3\% e 99,4\%, respectivamente. A desvantagem dos primeiros ao nível da esperança de vida não permite, no entanto, obter a progressividade global do sistema.

\section{(iv) Cenário 4: Diferenciar a taxa de formação das pensões}

Uma outra medida que tem sido discutida em Portugal é a diferenciação da taxa de formação das pensões de acordo com a categoria de rendimento. Apresentam-se, a seguir, dois cenários possíveis de diferenciação da taxa de formação das pensões, com graus diferentes de generosidade e de progressividade, mantendo-se, em tudo o resto, as regras do cenário-base onde a actual taxa é, como se referiu atrás, de $2 \%$ por cada ano com registo de remunerações.

a) Taxa de 2,5\% para os Profissionais Não Qualificados; 2\% para os Profissionais Qualificados; e 1,5\% para os Quadros Superiores, correspondendo a uma taxa de substituição da remuneração média de $100 \%, 80 \%$ e $60 \%$, respectivamente.

Quadro 6

\section{RESULTADOS DO CENÁRIO 4A}

\begin{tabular}{|l|c|c|}
\hline & TIR (\%) & Rácio B/C \\
\hline$\underline{\text { Homens }}$ & $-1,141$ & 0,335 \\
Quadros Superiores & $-0,356$ & 0,411 \\
Profissionais Qualificados & 0,153 & 0,470 \\
Prof. Não Qualificados & 311,9 & - \\
\hline Índice da Variância* & & \\
\hline & & \\
Mulheres & $-0,202$ & 0,397 \\
\hline Quadros Superiores & 0,504 & 0,484 \\
Profissionais Qualificados & 0,997 & 0,559 \\
Prof. Não Qualificados & 377,9 & - \\
\hline Índice da Variância* & & \\
\hline
\end{tabular}

* Cenário-Base $=100$ 
Os resultados reflectem, pela primeira vez, um sistema de segurança social progressivo, com taxas de rendibilidade positivas para os Profissionais Não Qualificados de ambos os sexos, obtidas à custa de uma forte penalização dos Quadros Superiores (comparando com o cenário-base). Esta redistribuição dos mais ricos para os mais pobres é igualmente visível no rácio entre benefícios e custos. Comparando as rendibilidades obtidas pelos dois sexos, mantém-se, tal como nos cenários anteriores, uma redistribuição a favor das mulheres.

b) Taxa de 3\% para os Profissionais Não Qualificados; 2,5\% para os Profissionais Qualificados; e 2\% para os Quadros Superiores, correspondendo a uma taxa de substituição da remuneração média de $120 \%, 100 \%$ e $80 \%$, respectivamente.

Quadro 7

RESULTADOS DO CENÁRIO 4B

\begin{tabular}{|l|c|c|}
\hline & TIR (\%) & Rácio B/C \\
\hline$\underline{\text { Homens }}$ & $-0,002$ & 0,446 \\
Quadros Superiores & 0,518 & 0,513 \\
Profissionais Qualificados & 0,863 & 0,563 \\
Prof. Não Qualificados & 139,2 & - \\
\hline Índice da Variância* & & \\
\hline & & \\
Mulheres & 0,820 & 0,529 \\
\hline Quadros Superiores & 1,288 & 0,605 \\
Profissionais Qualificados & 1,635 & 0,670 \\
Prof. Não Qualificados & 174,0 & - \\
\hline Índice da Variância* & & \\
\hline
\end{tabular}

* Cenário-Base $=100$

O sentido dos resultados não se altera face ao cenário $4 \mathrm{a}$, variando apenas o grau de progressividade e o facto de nenhuma categoria ser penalizada face aos resultados do cenário-base. 
(v) Cenário 5: Diferenciar a taxa de actualização real das pensões

Até aqui, foi sempre assumido que o valor real das pensões se mantinha constante ao longo de todo o período de reforma. Na prática, no entanto, isso não acontece. Embora ao longo da última década os Governos tenham feito um esforço de actualização anual das pensões, nem sempre o seu valor real é mantido. Por outro lado, nos últimos anos, o Governo introduziu a chamada "discriminação positiva" na actualização anual das pensões, sendo o aumento superior para os escalões de pensões mais baixos. Em 2001, os aumentos foram de 5,9\% para a pensão mínima; 3,5\% para pensões até 300 contos; e 2,9\% (até um limite máximo de 18 contos) para pensões superiores àquele valor, pelo que apenas a pensão mínima viu o seu valor real aumentado. Apresentam-se, a seguir, quatro cenários de actualização diferenciada das pensões.

a) No cenário 5a as taxas de actualização para os Profissionais Não Qualificados, para os Profissionais Qualificados e para os Quadros Superiores são iguais a $2 \%, 1 \%$ e $0 \%$, respectivamente;

Quadro 8

RESULTADOS DO CENÁRIO 5A

\begin{tabular}{|l|c|c|}
\hline & TIR (\%) & Rácio B/C \\
\hline$\underline{\text { Homens }}$ & $-0,002$ & 0,446 \\
Quadros Superiores & $-0,096$ & 0,436 \\
Profissionais Qualificados & $-0,247$ & 0,421 \\
Prof. Não Qualificados & 11,2 & - \\
\hline Índice da Variância* & & \\
\hline & & \\
Mulheres & 0,820 & 0,529 \\
\hline Quadros Superiores & 0,800 & 0,524 \\
Profissionais Qualificados & 0,771 & 0,519 \\
Prof. Não Qualificados & 0,6 & - \\
\hline Índice da Variância* & & \\
\hline
\end{tabular}

* Cenário-Base $=100$ 
b) Taxas de actualização iguais a 2,5\%,1,5\% e $0 \%$;

\section{Quadro 9 \\ RESULTADOS DO CENÁRIO 5B}

\begin{tabular}{|l|c|c|}
\hline & TIR (\%) & Rácio B/C \\
\hline Homens & & \\
Quadros Superiores & $-0,002$ & 0,446 \\
Profissionais Qualificados & 0,033 & 0,450 \\
Prof. Não Qualificados & $-0,125$ & 0,433 \\
\hline Índice da Variância* & 5,1 & - \\
\hline & & \\
Mulheres & & \\
Quadros Superiores & 0,820 & 0,529 \\
Profissionais Qualificados & 0,948 & 0,545 \\
Prof. Não Qualificados & 0,913 & 0,539 \\
\hline Índice da Variância* & 4,6 & - \\
\hline
\end{tabular}

* Cenário-Base $=100$

c) Taxas de actualização iguais a 3\%, 1,5\% e $0 \%$; 
Quadro 10

RESULTADOS DO CENÁRIO 5C

\begin{tabular}{|l|c|c|}
\hline & TIR (\%) & Rácio B/C \\
\hline Homens & $-0,002$ & 0,446 \\
\hline Quadros Superiores & 0,033 & 0,450 \\
Profissionais Qualificados & $-0,004$ & 0,446 \\
Prof. Não Qualificados & 0,3 & - \\
\hline Índice da Variância* & & \\
\hline & & \\
Mulheres & 0,820 & 0,529 \\
\hline Quadros Superiores & 0,948 & 0,545 \\
Profissionais Qualificados & 1,054 & 0,560 \\
Prof. Não Qualificados & 14,3 & - \\
\hline Índice da Variância* & & \\
\hline
\end{tabular}

* Cenário-Base $=100$

d) Taxas de actualização iguais a 3,5\%,2\% e $0 \%$.

Quadro 11

RESULTADOS DO CENÁRIO 5D

\begin{tabular}{|l|c|c|}
\hline & TIR (\%) & Rácio B/C \\
\hline Homens & $-0,002$ & 0,446 \\
\hline Quadros Superiores & 0,162 & 0,464 \\
Profissionais Qualificados & 0,117 & 0,459 \\
Prof. Não Qualificados & 5,3 & - \\
\hline Índice da Variância* & & \\
\hline & & \\
Mulheres & 0,820 & 0,529 \\
\hline Quadros Superiores & 1,095 & 0,567 \\
Profissionais Qualificados & 1,195 & 0,583 \\
Prof. Não Qualificados & 39,2 & - \\
\hline Índice da Variância* & & \\
\hline
\end{tabular}

* Cenário-Base $=100$ 
Embora a actualização real das pensões dos Quadros Superiores tenha sido mantida a zero ao longo destes quatro cenários (tal como no cenário-base), a taxa interna de rendibilidade dos homens Profissionais Não Qualificados apenas surge como superior à dos primeiros quando o valor real das suas pensões é actualizado à taxa de $3,5 \%$, no cenário $5 \mathrm{~d}$. No caso das mulheres, o sistema torna-se globalmente progressivo com uma taxa de $3 \%$, no cenário $5 \mathrm{c}$ (embora, no cenário $5 \mathrm{~b}$, a rendibilidade obtida pelos Profissionais Não Qualificados seja já superior à dos Quadros Superiores). No caso dos homens, os Profissionais Qualificados são os mais beneficiados nos cenários $5 \mathrm{~b}, 5 \mathrm{c}$ e $5 \mathrm{~d}$, devido à combinação do perfil de remunerações, esperança de vida e actualização real das pensões (sendo este último aspecto, em particular, que explica os ganhos obtidos face aos Quadros Superiores). O primeiro cenário, com aumentos de $2 \%$ e $1 \%$ para os Profissionais Não Qualificados e para os Profissionais Qualificados, respectivamente, limita-se a atenuar ligeiramente a regressividade do cenário-base.

\section{vi) Cenário 6: Introduzir uma componente de capitalização}

Uma das estratégias mais discutidas em termos da reforma da segurança social é a introdução de uma componente de capitalização, transformando o sistema pay-as-you-go num sistema misto e atenuando, dessa forma, a sua dependência relativamente à evolução demográfica desfavorável. A análise desta medida, que a seguir se apresenta, é feita de uma forma muito simplificada, ignorando-se o facto de o aumento da poupança gerado pelo desvio de uma parte das contribuições para capitalização ter implicações económicas que podem interferir nos próprios perfis de remunerações (e, no longo prazo, na própria esperança de vida). Por outro lado, ignoram-se também os problemas relacionados com a transição para um sistema misto como, por exemplo, o facto de o sistema pay-as-you-go prescindir, a partir de determinada altura, de uma parcela das suas receitas sem contrapartidas nas despesas.

Assume-se agora que $25 \%$ das contribuições para o sistema pay-as-you-go passam a ser canalizadas para uma conta individual em sistema de capitalização, sendo também a pensão estatutária reduzida em $25 \%$ (isto é, o limite superior para o montante da pensão passa a ser igual a $60 \%$ da remuneração média). Todas as outras regras actuais se mantêm. Consideram-se três cenários alternativos, de acordo com a rendibilidade obtida pela conta individual: no cenário $6 \mathrm{a}$, admite-se uma rendibilidade 
de $4 \%$ ao ano, no cenário $6 \mathrm{~b}$ uma rendibilidade de $1 \%$ e no cenário $6 \mathrm{c}$ uma rendibilidade de $0 \%$.

Por último, foi também assumida uma hipótese forte relativamente ao tratamento do produto da capitalização no momento da reforma. O procedimento típico passa pela compra obrigatória de uma anuidade ou por levantamentos faseados. Nos países da América Latina, onde mercados de anuidades se desenvolveram com as reformas da segurança social, existem em média mais de 100 produtos diferentes com anuidades, que se adaptam às características particulares dos aforradores. No entanto, dada a simplicidade da nossa simulação, optou-se por considerar um pagamento lump sum da totalidade do montante capitalizado no momento da reforma, devendo por isso os resultados ser interpretados com cuidado.

a) Rendibilidade anual de $4 \%$;

Quadro 12

RESULTADOS DO CENÁRIO 6A

\begin{tabular}{|l|c|c|}
\hline & TIR (\%) & Rácio B/C \\
\hline$\underline{\text { Homens }}$ & 1,134 & 0,644 \\
Quadros Superiores & 0,945 & 0,618 \\
Profissionais Qualificados & 0,753 & 0,592 \\
Prof. Não Qualificados & 26,6 & - \\
\hline Índice da Variância* & & \\
\hline & & \\
Mulheres & 1,621 & 0,707 \\
\hline Quadros Superiores & 1,432 & 0,675 \\
Profissionais Qualificados & 1,258 & 0,647 \\
Prof. Não Qualificados & 34,3 & - \\
\hline Índice da Variância* & & \\
\hline
\end{tabular}

* Cenário-Base $=100$

b) Rendibilidade anual de $1 \%$; 
Quadro 13

RESULTADOS DO CENÁRIO 6B

\begin{tabular}{|l|c|c|}
\hline & TIR (\%) & Rácio B/C \\
\hline Homens & 0,008 & 0,446 \\
\hline Quadros Superiores & $-0,059$ & 0,475 \\
Profissionais Qualificados & $-0,335$ & 0,448 \\
Prof. Não Qualificados & 24,3 & - \\
\hline Índice da Variância* & & \\
\hline & & \\
Mulheres & 0,845 & 0,564 \\
\hline Quadros Superiores & 0,593 & 0,529 \\
Profissionais Qualificados & 0,357 & 0,500 \\
\hline Prof. Não Qualificados & 62,0 & - \\
\hline Índice da Variância* &
\end{tabular}

* Cenário-Base $=100$

c) Rendibilidade anual de $0 \%$.

Quadro 14

RESULTADOS DO CENÁRIO 6C

\begin{tabular}{|l|c|c|}
\hline & TIR (\%) & Rácio B/C \\
\hline Homens & $-0,002$ & 0,475 \\
\hline Quadros Superiores & $-0,283$ & 0,447 \\
Profissionais Qualificados & $-0,580$ & 0,420 \\
Prof. Não Qualificados & 61,3 & - \\
\hline Índice da Variância* & & \\
\hline & & \\
Mulheres & 0,679 & 0,536 \\
Quadros Superiores & 0,413 & 0,501 \\
Profissionais Qualificados & 0,163 & 0,472 \\
Prof. Não Qualificados & 69,3 & - \\
\hline Índice da Variância*
\end{tabular}

* Cenário-Base $=100$ 
O primeiro resultado a destacar é a subida da taxa interna de rendibilidade em todos os cenários e para todos os grupos de rendimento. Mesmo quando esta taxa se mantém negativa, como no cenário $6 \mathrm{c}$ e $6 \mathrm{~b}$ (este no caso das duas categorias de rendimentos mais baixas), a situação é mais favorável do que no cenário-base.

O segundo resultado a referir é o de que, embora o sistema se mantenha regressivo, a dispersão das rendibilidades é muito inferior à observada no cenário-base, em particular no cenário $6 \mathrm{a}$, onde se assume um retorno anual de $4 \%$. A regressividade do sistema é, assim, fortemente atenuada pela introdução de uma componente de capitalização.Como foi referido atrás, é necessário interpretar com cuidado estas conclusões. Ao assumir-se o pagamento lump sum da totalidade do produto da capitalização no momento da reforma, ignoram-se os efeitos redistributivos implícitos num esquema de anuidades, como o facto de se manter, tal como no actual sistema pay-as-you-go puro, a redistribuição perversa gerada pelas diferentes esperanças de vida dos vários grupos de rendimento. Para além disto, ignoraram-se igualmente os efeitos redistributivos presentes na fase de acumulação da pensão. Por exemplo, as pessoas mais pobres têm, em geral, menores conhecimentos sobre o sector financeiro, pelo que a escolha informada de uma boa empresa gestora de fundos pode-se tornar mais difícil, pondo em causa a rendibilidade obtida pelas suas poupanças. Por outro lado, estas empresas tendem a cobrar comissões elevadas ou, em alguns casos, comissões de valor fixo. Como se viu atrás, isto representa um sacrifício maior para os grupos de rendimentos mais baixos.

\section{CONCLUSÕES}

Procurou-se, neste artigo, relacionar os problemas estruturais da segurança social com o objectivo da redistribuição do rendimento, argumentando-se que, ao contrário das intenções explícitas dos sistemas públicos de repartição contemporânea, as regras de cálculo das pensões de velhice potenciam uma redistribuição perversa do rendimento, dos mais pobres para os mais ricos (para além de uma redistribuição não intencional entre gerações).

Observando os resultados empíricos de diversos estudos, relativos a vários países, concluiu-se que, onde a natureza progressiva da segurança 
social se mantém, ela é pouco significativa e não sistemática. Em alguns países, existe evidência de que os sistemas assumiram, de facto, uma natureza regressiva.

São várias as justificações para este tipo de efeitos redistributivos. Essencialmente, as regras dos sistemas de repartição contemporânea privilegiam os comportamentos no mercado de trabalho tipicamente associados a trabalhadores de maiores rendimentos e prejudicam as categorias profissionais associadas a um maior risco ocupacional. Outra justificação prende-se com a ideia de que um sistema de segurança social em regime de repartição contemporânea está permanentemente sujeito a riscos políticos. De facto, por não existir uma ligação actuarial entre contribuições e benefícios, as regras do sistema estão permanentemente sujeitas à intervenção discricionária dos governos, com implicações ao nível da distribuição do rendimento.

Na última parte do trabalho, procedeu-se a uma simples simulação de perfis de remuneração e, aplicando as regras do regime geral da segurança social portuguesa, procurou-se avaliar a existência e o sentido dos efeitos redistributivos em Portugal. Os resultados confirmam a natureza regressiva do sistema de repartição contemporânea e apontam também para uma redistribuição a favor das mulheres, à custa dos homens. Foram também simulados os efeitos de alguns ajustamentos nas regras, concluindo-se que os melhores resultados, tendo como único critério a progressividade do sistema, são obtidos introduzindo no sistema actual uma diferenciação na taxa de formação das pensões. Num dos cenários considerados, a introdução de uma componente de capitalização reduziria fortemente a regressividade do sistema e permitiria, para todas as categorias de rendimento, o maior aumento da rendibilidade das contribuições. A recente proposta do governo no sentido de se passar a considerar toda a carreira no cálculo das pensões (em vez dos 10 melhores anos dos últimos 15 antes da reforma) reduz a taxa interna de rendibilidade para todos os grupos considerados mas atenua também a regressividade do sistema.

Uma característica importante dos efeitos redistributivos descritos neste artigo é a sua natureza implícita e não declarada, que impede a sociedade de os conhecer e, consequentemente, de os validar ou rejeitar explicitamente. Na generalidade dos países onde se procurou conhecer a fundo e divulgar os efeitos económicos e sociais dos sistemas de segurança social, a sua insustentabilidade financeira e os efeitos redistributivos indesejados levaram à escolha da transição para sistemas mistos, mantendo uma componente de redistribuição contemporânea 
pública e introduzindo uma componente importante de capitalização (pública ou, na maior parte dos casos, privada).

\section{NOTAS}

* O autor agradece o apoio financeiro prestado pela Fundação para a Ciência e Tecnologia.

${ }^{1}$ Tradução do original "social regressive impact".

2 Existe, actualmente, uma vasta evidência empírica relacionando a categoria socioeconómica com a mortalidade e a esperança de vida. Veja-se, por exemplo, os trabalhos de Kitagawa e Hauser (1973), Sorlie et al. (1992), Adam (1995), Garrett (1995), Kaplan (1996), Lantz et al. (1998), Deaton e Paxson (1999), Nelissen (1999) e Brown (2000). Três medidas têm sido, habitualmente, utilizadas para estimar esta relação: o nível de educação, o rendimento e a riqueza. No caso da educação, é possível que os anos de escolaridade funcionem como uma proxy do rendimento, mas pode igualmente admitir-se que um maior nível de educação reflicta uma melhor compreensão das regras de comportamento associadas a uma vida mais saudável.

${ }^{3}$ A Hungria encontra-se, neste momento, numa fase de transição para um sistema de segurança social misto, com componentes de repartição contemporânea pública e de capitalização privada.

${ }^{4}$ Parece também existir evidência (ver, por exemplo, Gil e Lopez-Casasnovas, 1997) de que os trabalhadores casados obtêm uma rendibilidade das contribuições superior à dos trabalhadores solteiros. Por um lado, os primeiros beneficiam de prestações de sobrevivência e viuvez em caso de morte do cônjuge. Por outro lado, as pessoas solteiras têm menor esperança de vida do que as casadas, recebendo assim a pensão de velhice durante menos tempo. Uma justificação para este facto pode estar no apoio recíproco prestado pelos cônjuges, quer ao nível da criação e manutenção de hábitos de saúde, quer ao nível do apoio psicológico, evitando os problemas sentidos por pessoas a viver isoladas.

${ }^{5}$ Ver demonstração e explicação detalhada do modelo em Creedy (1992). O processo descrito baseia-se também na evidência de que a dispersão de remunerações dos perfis cross-section não é significativamente diferente daquela observada nos perfis lifetime.

${ }^{6}$ Trata-se, obviamente, de uma simplificação, dada a impossibilidade de obter dados reais sobre a esperança de vida na idade de reforma, segundo as categorias profissionais consideradas. Os valores obtidos podem, no entanto, ser considerados razoáveis. São, para além disso, consistentes com a realidade demográfica portuguesa e reflectem em termos de diferencial, resultados bastante consistentes da literatura. 
${ }^{7}$ Desde 1999, existe a possibilidade legal de requerer a pensão de reforma a partir dos 55 anos, desde que se tenham completado 30 anos com registo de remunerações. Neste caso, a pensão estatutária sofre uma redução de $4,5 \%$ por cada ano de antecipação. Por outro lado, é possível requerer a pensão depois dos 65 anos (desde que se tenham completado 40 anos de remunerações), caso em que o valor estatutário da pensão é acrescido de uma bonificação resultante do produto de uma taxa de $10 \%$ pelo número de anos com registo de remunerações verificados a partir dos 65 anos (com o limite de 70 anos).

\section{REFERÊNCIAS}

ADAM, L. (1995), “Canadian Pensioners Mortality Table 1983-1992, A Report on the Construction of a Mortality Table Based on C/QPP Experience Data", draft. Quebec: University Laval.

ATKINSON, A. (1987), "Income Maintenance and Social Insurance", Chapter 13 in Handbook of Public Economics, vol. II, eds. A. Auerbach e M. Feldstein, North Holland.

BORELLA, M. (2001), "Social Security Systems and the Distribution of Income: An Application to the Italian Case", Center for Research on Pensions and Welfare Policy, Working Paper $n^{\circ} 8 / 01$.

BOSWORTH, B.; BURTLESS, G. e SAHM C. (2000), "Distributional Impact of Social Security Reform", artigo apresentado na $2^{\text {a }}$ Conferência Annual do Retirement Research Consortium, The Outlook for Retirement Income.

BROWN, J. R. (2000), "Differential Mortality and the Value of Individual Account Retirement Annuities", artigo apresentado na conferência do NBER Distributional Aspects of Social Security and Social Security Reform.

BROWN, R. L. (1997), “Social Security: Regressive or Progressive?", North American Actuarial Journal, vol.2, n², p.1-33.

CASTELlinO, O. (1995), "Redistribution Between and Within Generations in the Italian Social Security System”, Ricerche Economiche, 49, p. 317-327.

CLBSS (1998), Livro Branco da Segurança Social.

CREEDY, J. (1992), "Earnings Comparisons Between Generations", in Income, Inequality and the Life Cycle, ed. Creedy, J., Edward Elgar.

CUBEDDU, L. (2000), "Intragenerational Redistribution in Unfunded Pension Systems”, IMF Staff Papers, vol. $47, n^{\circ} 1$. International Monetary Fund. 
DEATON, A. e PAXSON. C. (1999), "Mortality, Education, Income and Inequality Among American Cohorts", NBER Working Paper n'7140.

DEATON, A.; GOURINCHAS P. e PAXSON C. (2000), "Social Security and Inequality over the Life Cycle", artigo apresentado na NBER Conference on the Distribution Effects of Social Security Reform.

FELDSTEIN, M. (1985), “The Optimal Level of Social Security Benefits”, Quarterly Journal of Economics, $\mathrm{C} \mathrm{n}^{\circ} 2$, p.303-320.

FELDSTEIN, M. e LIEBMAN, J. (2000), "The Distributional Effects of an Investment-Based Social Security System”, NBER Working Paper 7492, National Bureau of Economic Research.

GARRETT, D. M. (1995), "The Effects of Differential Mortality Rates on the Progressivity of Social Security”, Economic Inquiry, Vol.33, Julho.

GIL, J. e LOPEZ-CASANOVAS, G. (1997), "Life-Time Redistribution Effects of the Spanish Public Pension System", mimeo.

GIRALDES, M. R. (1996), Desigualdades Sócio-Económicas e seu Impacte na Saúde, Editorial Estampa.

HURD, M. D. e SHOVEN, J. B. (1985), "The Distributional Impact of Social Security", in Pensions, Labour and Individual Choice, ed. Wise, D., Chicago University Press.

INE (1999), Estatísticas Demográficas, Gabinete de Estudos e Conjuntura.

JAMES, E. (1997), "Pension Reform: Is There An Efficiency-Equity Trade-Off?", artigo apresentado na conferência Inequality Reducing Growth in Latin American's Market Economies (Inter-American Development Bank).

KAPLAN, G. A.; PAMUK, E. R.; LYNCH, J. W.; COHEN, R. D. e BALFOUR, J. L (1996), "Inequality in Income and Mortality in the United States: Analysis of Mortality and Potential Pathways", BMJ, vol. 312, Abril.

KITAGAWA, E. e HAUSER, P. (1973), Differential Mortality in the United States: A Study in Socioeconomic Epidemiology, Cambridge, Mass.: Harvard University Press.

KOTLIKOFF. L. J.; SMETTERK, S e WALLISER, J. (2000), "Distributional Effects in a General Equilibrium Analysis of Social Security", mimeo.

LANTZ, P. M.; HOUSE, J. S.; LEPKOWSKI, J. M.; WILLIAMS, D. R.; MERO, R. P. e CHEN J. (1998), "Socioeconomic Factors, Health Behaviours and Mortality", Journal of the American Medical Association, Vol.279, n²1, Junho.

MTS (2001), Pensão por Velhice (Regime Geral): Condições de Atribuição e Montante, no site do Ministério do Trabalho e Solidariedade, http://193.126.192/preview_pag.asp?r=2744 em 7/5/2001. 
NELISSEN J. (1999), "Mortality Differences related to socioeconomic status and the progressivity of old-age pensions and health insurance: The Netherlands", European Journal of Population 15: (1) p.77-97, Março.

RAKE, K.; FALKINGHAM, J. e EVANS, M. (1999), "Tightropes and Tripwires: New Labour's Proposals and Means-Testing in Old Age”, CASE Paper 23, Centre for Analysis of Social Exclusion, London School of Economics.

REGIDOR, E.; DE MATEO, S.; GUTIERREZ-FISAC, J. L. e RODRIGUEZ, C. (1996), "Diferencias socioeconómicas en mortalidad en ocho provincias españolas”, Medicina Clínica, vol.106, nº 8 , p. 285-289.

SANTOS LUCAS, J. (1987), "Iniquidade Social Perante a Doença e a Morte em Portugal", in Sociedade, Saúde e Economia, Actas das V Jornadas de Economia da Saúde, ENSP, Lisboa.

SORLIE, P.; ROGOT, E.; ANDERSON, R.; JOHNSON, N. e BACKLUND, E. (1992), "Black-White Mortality Differences by Family Income", Lancet 340 (Agosto): 346-50.

STAHLBERG, A. C. (1994), "Swedish Women's Pensions", artigo apresentado na 8 a Reunião Anual da European Society for Population Economics.

WORLD BANK (1994), Averting the Old Age Crisis (World Bank Policy Research Report), Oxford University Press. 